\title{
Mechanical Behaviour and Microstructure Characteristic of Concrete by Using Freshwater and Seawater
}

\author{
Mansyur ${ }^{a^{*}}$, Dian Permana ${ }^{a}$ \\ ${ }^{a}$ Universitas Sembilanbelas November Kolaka, Jl. Pemuda No. 339 Kolaka, Kolaka 93517, Indonesia.
}

Received 16 February 2020; Accepted 16 April 2020

\begin{abstract}
The development of infrastructure in archipelago countries often faces difficulties and challenges due to the lack of fresh water. Hence, in some cases, the usage of seawater is favourable, in particular for concrete making. Little studies have been conducted on comparing the seawater, and freshwater concretes, especially on microstructure analysis. The objective of this study was to reveal the compressive strength, elasticity, and microstructure of concrete using seawater and freshwater as the mixing water. The methodology of this study was mix design, making test specimens, curing test specimens, and microstructure analysis. The tests of concretes were conducted for each sample with variations of $1,3,7$, and 28 days and the mechanical behavior were tested using compressive strength and elasticity as parameters. At the same time, the microstructure was examined using an X-Ray Diffraction (XRD). The results showed an increase in compressive strength and elasticity of seawater and freshwater concretes at all variations with insignificant differences observed between the two types of concretes. It was also discovered that the formation of Friedel's salt $\left(3 \mathrm{CaO} \cdot \mathrm{Al}_{2} \mathrm{O}_{3} \cdot \mathrm{CaCl}_{2} \cdot 10 \mathrm{H}_{2} \mathrm{O}\right)$ in the seawater concrete was not in the freshwater concrete. In conclusion, the differentiation of microstructure did not significantly affect the compressive strength and elasticity between seawater and freshwater in mixing concrete.
\end{abstract}

Keywords: Compressive Strength; Concrete; Elasticity; Freshwater; Microstructure; Seawater.

\section{Introduction}

There is currently a very rapid development in concrete technology and several innovative research works have been conducted to improve the quality of concrete, especially with a bid to finding solutions to many problems observed in the materials used for mixing and overcoming the problems arising from the use of these concretes in the field. The significant challenges faced by engineers is the lack of clean water to be used in mixing, workability, work processes, especially structures with complex reinforcement, high structure, and negligence in the maintenance.

A shortage of freshwater supplies raised global consideration to use seawater as an option for concrete mixing [1]. Recently, seawater and sand containing chloride are used as mixing materials in some parts of the world. In some developed countries, civil engineers have thought about the future challenges of reducing the use of clean water for this process, considering the increase in infrastructural development [2]. Freshwater and seawater might contain impurities that affect the quality of mixing water for concrete. Fortunately, the presence of impurities has shown a favourable effect on strength development at early ages and strength reduction in a long duration of time [3]. The utilization of seawater and sea-sand in concrete construction has been reviewed previously. Studies have shown the benefit of sea-sand and seawater to produce faster early strength of concrete as compared to ordinary concrete. Instead,

* Corresponding author: mansyurusn14@gmail.com

http://dx.doi.org/10.28991/cej-2020-03091540

(C) 2020 by the authors. Licensee C.E.J, Tehran, Iran. This article is an open access article distributed under the terms and conditions of the Creative Commons Attribution (CC-BY) license (http://creativecommons.org/licenses/by/4.0/). 
both types of concrete achieved comparable long-term strength [4]. Alrowaih and Alruwayeh [5] reported the effect of salts like sodium chloride at varied concentrations as curing for the mechanical strength of solid concrete cubes and specimens. Moreover, salts content in seawater found to increase the compressive, tensile, flexural, and bond strengths of the concrete [6]. Teng et al. [7] developed a new type of ultra-high-performance concrete for marine construction using seawater and sea-sand as a solution of freshwater, river-sand, and coarse aggregate shortages. More studies reported the compressive strength and slump flow of self-compacting concrete (SCC) using two types of water [8] and self-compacting concrete using seawater as mixing water without curing method [9].

The microstructure analysis of concrete made using seawater and freshwater as mixing and curing water showed a comparison of their properties, including fresh and hardened properties [10] and particular components [10]. The presence of components in concrete play a function for its microstructure, thus controlling the behavior is possible [11]. Another study showed beneficial relationships between compressive strength and microstructure characteristics of self-compacting concrete analyzed up to 90 days ages when using seawater [12].

Indonesia is an archipelagic nation with most of its areas lacking quality water sources for drinking, not to mention the freshwater for infrastructure purposes. The limitation of the quantity of freshwater in several regions led to the inevitable use of seawater in mixing and maintaining concretes, especially for buildings located in coastal areas like port. As far as our concern, the relationship between immersion time and microstructure characteristics of concrete made using seawater and freshwater has yet investigated. Hence, in this study, we reported the compressive strength, elasticity, and microstructure of concrete using seawater and freshwater as mixing water.

\section{Research Methodology}

The materials used in the study were Portland Composite Cement (PCC), freshwater, seawater, local crushed stone at a maximum size of $20 \mathrm{~mm}$, local sand at 4.75 , and superplasticizer. The research was conducted in the laboratory using an experimental method. The self-compacting concrete (SCC) was designed using European Federation of Specialist Chemical Concrete Construction Systems method, and the SCC was mixed using water and cement with a volume ratio of 1:1. Figure 1 shows the flowchart of the research methodology.

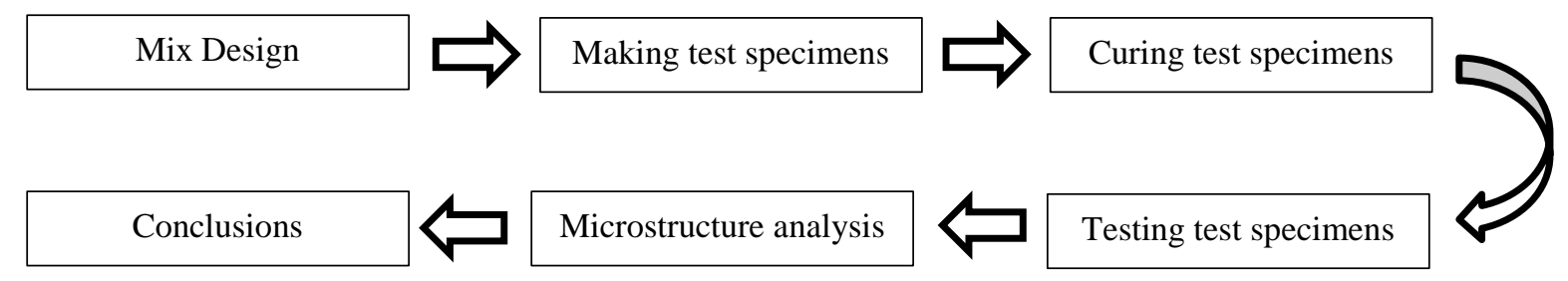

Figure 1. Flowchart of the research methodology

All the ingredients were mixed in three consecutive stages. First, fine sand and coarse aggregate in Saturated Surface Dry (SSD) condition were mixed for $\pm 1 \mathrm{~min}$. Second, the cement was poured into the concrete-mixing machine containing the aggregate and mixed for about 1-2 minutes. Third, after a homogenous mixture was achieved, the water was mixed with superplasticizer, incorporated into the concrete, and mixed for about 2-3 minutes. The mixture was homogenized using a concrete mixer. However, using a water-cement factor of 0.37 , the 32 cylindrical concrete made from seawater contained $32.98 \mathrm{~kg}$ of water, $93.15 \mathrm{~kg}$ of cement, $90.57 \mathrm{~kg}$ of sand and $187.06 \mathrm{~kg}$ of crushed stones while 32 samples produced from freshwater had $33.79 \mathrm{~kg}$ of water, $93.99 \mathrm{~kg}$ of cement, $71.62 \mathrm{~kg}$ of sand and $203.51 \mathrm{~kg}$ of crushed stones. After the measurements and observations, the SCC was inserted into the $150 \times$ $300 \mathrm{~mm}$ cylinder size. Furthermore, 28 cylinders were made for each of the samples and the specimens were tested before treatment, and for 1, 3, 7, and 28 days. The seawater concrete was denoted by SCC-SC and freshwater concrete by SCC-FC. The photo of the cylinder concrete sample model is shown in Figure 2.

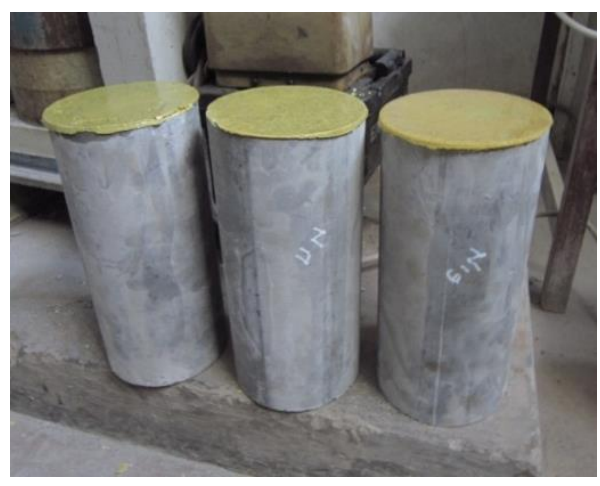

Figure 2. Cylinder Concrete Sample Model 
The two mechanical tests conducted were on the compressive and tensile strength at 1, 3, 7, and 28 days with each treatment having three samples. The standard test for the compressive strength was conducted according to the Indonesian National Standards (SNI) with the number 1974-2011. Moreover, Equipment Universal Testing Machine (UTM) was used by providing a static monotonic uniaxial compressive load at an average speed of 0.14 to 0.34 $\mathrm{MPa} / \mathrm{sec}$ and the value was calculated using the following equation:

$F C^{\prime}=\frac{P}{A}$

Where $F c^{\prime}$ is the concrete compressive strength in $\mathrm{MPa}, \mathrm{P}$ is Peak load in $\mathrm{N}$, and $\mathrm{A}$ is the surface area of the cylinder in $\mathrm{mm}$.

Furthermore, the standard test to split tensile strength was conducted based on the SNI with the number 03-24912002 and the value was obtained using the following equation:

$T=\frac{2 P}{\pi L D}$

Where $\mathrm{T}$ is splitting tensile strength in $\mathrm{MPa}, \mathrm{P}$ is the maximum applied load indicated by the testing machine in $\mathrm{N}, \mathrm{L}$ is the length in $\mathrm{mm}$, and $\mathrm{D}$ is the diameter in $\mathrm{mm}$.

The microstructural characteristics of the concrete were studied using molecular microstructure testing through the use of X-Ray Diffraction. The analysis was conducted on both types of concrete on the first, second, seventh, and twenty-eighth day. Data obtained from the tests were analyzed using regression analysis through the use of mechanical testing as the dependent variable and microstructure as the independent variable.

Table 1. The Types and amount of testing

\begin{tabular}{lcccccc}
\hline \multirow{2}{*}{ Concrete } & \multirow{2}{*}{ Test } & \multirow{2}{*}{ Form of a test object } & \multicolumn{3}{c}{ Number of Test Items for Immersion } \\
\cline { 4 - 6 } & & & $\mathbf{1}$ day & $\mathbf{3}$ days & $\mathbf{7}$ days & $\mathbf{2 8}$ days \\
\hline \multirow{3}{*}{ SCC-FC } & Compressive strength & Cylinders $(150 \times 300) \mathrm{mm}$ & 3 & 3 & 3 & 3 \\
& Tensile & Cylinders $(150 \times 300) \mathrm{mm}$ & 3 & 3 & 3 & 3 \\
& Microstructure & Cylinders $(150 \times 300) \mathrm{mm}$ & 1 & 1 & 1 & 1 \\
\multirow{3}{*}{ SCC-SC } & Compressive strength & Cylinders $(150 \times 300) \mathrm{mm}$ & 3 & 3 & 3 & 3 \\
& Tensile & Cylinders $(150 \times 300) \mathrm{mm}$ & 3 & 3 & 3 & 3 \\
& Microstructure & Cylinders $(150 \times 300) \mathrm{mm}$ & 1 & 1 & 1 & 1 \\
\hline
\end{tabular}

\section{Results and Discussion}

\subsection{Compressive Strength}

This is the most important mechanical property in determining the quality of concrete. It was calculated using the ratio comparison of cement, coarse and fine aggregates, water, and several mixtures. The results obtained for both SCC-SC and SCC-FC are shown in Table 2.

Figure 3 shows SCC the compressive strength of the two treatments to be increasing with the duration. However, the values obtained for SCC-SC is slightly higher than SCC-FC towards the 28th day. This in agreement with the previous research c onducted by Bachtiar et al. (2013 and 2014) [12,13] which showed the compressive strength of both mortar and concrete using seawater to be higher than for distilled water or freshwater. Moreover, the value obtained was observed to have improved for the SCC-SC from 1st to 3rd, 3rd to 7th, and 7th to 28th day by $24.16 \%, 39.92 \%, 67.44 \%$ respectively and the value at the last day was $44.88 \mathrm{MPa}$. The differences between the SCC-SC and SCC-FC for these periods were $23.13 \%, 39.83 \%$, and $67.88 \%$ respectively, and the value for the SCC-FC on the last day was $44.03 \mathrm{MPa}$.

Table 2. The compressive strength test of SCC-SC and SCC-FC

\begin{tabular}{ccccc}
\hline \multirow{2}{*}{ Samples } & \multicolumn{4}{c}{ Compressive strength fc' (MPa) } \\
\cline { 2 - 5 } & $\mathbf{1}$ day & 3 days & 7 days & 28 days \\
\hline \multirow{3}{*}{ SCC-SC } & 11.31 & 19.23 & 31.11 & 45.25 \\
& 10.75 & 16.97 & 29.70 & 44.40 \\
Average & 10.56 & 17.54 & 29.98 & 44.97 \\
& 10.84 & 17.91 & 30.26 & 44.88 \\
SCC-FC & 10.46 & 18.67 & 30.55 & 42.42 \\
& 10.18 & 15.84 & 29.41 & 44.69 \\
Average & 9.90 & 18.10 & 29.70 & 44.97 \\
\hline
\end{tabular}


The improvement in the values of the compressive strength for both SCC-SC and SCC-FC were observed in all the days. The strength of the concrete produced using the seawater may be increased due to the possibility of the formation of crystals, making the structure denser as a result of the salt content. This is in line with the study conducted [14], which showed the addition of sodium chloride in fresh concrete to lead to the formation of crystals of Friedel' salt $3 \mathrm{CaO} \cdot \mathrm{Al}_{2} \mathrm{O}_{3} \cdot \mathrm{CaCl}_{2} \cdot 10 \mathrm{H}_{2} \mathrm{O}$. This was observed to have the ability to improve the $\mathrm{pH}$ and alkalinity, which further activates the hydration of cement paste and provide a more solid structure with smaller pores. Another research by [15] also reported the presence of chloride to have accelerated the development of early age concrete strength slag up to about 7-14 days.

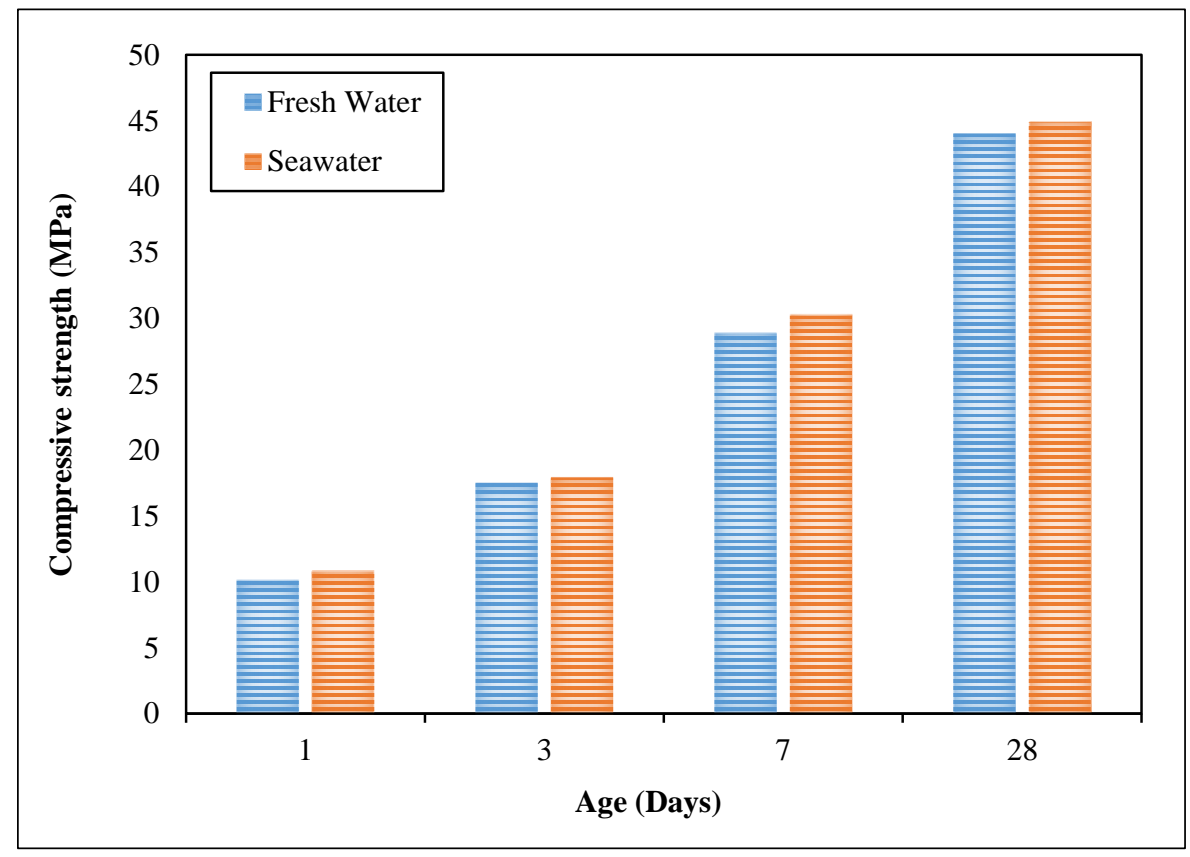

Figure 3. Compressive strength of SCC-FC and SCC-SC

\subsection{Splitting Tensile Strength}

The elasticity test conducted also showed the SCC-SC has the capability to provide modulus of elasticity almost the same as SCC-FC as shown in Table 3. Figure 4 shows the values of the splitting tensile strength increases with age. The values for SCC-SC were slightly higher than what was recorded for SCC-FC up to the 28th day. Moreover, the values were observed to have improved for the SCC-SC from 1st to 3rd, 3rd to 7th, and 7th to 28th day with 49.56\%, 64.83 , and $81.54 \%$ respectively and the value on the 28th day was $32209.46 \mathrm{MPa}$. Whereas, the improvement for the SCC-FC at the same age were $47.28 \%, 62.75 \%$, and $81.37 \%$ respectively with $31804.47 \mathrm{MPa}$ recorded for the 28 th day. These results are in agreement with the findings of the previous research works [16, 17].

Table 3. The splitting tensile strength test of SCC-SC and SCC-FC

\begin{tabular}{ccccc}
\hline \multirow{2}{*}{ Samples } & \multicolumn{4}{c}{ Splitting tensile strength (MPa) } \\
\cline { 2 - 5 } & $\mathbf{1}$ day & 3 days & $\mathbf{7 ~ d a y s}$ & $\mathbf{2 8 ~ d a y s}$ \\
\hline \multirow{2}{*}{ SCC-SC } & 16531.53 & 21983.10 & 27063.64 & 31343.86 \\
& 15899.95 & 20342.42 & 26307.82 & 32539.54 \\
& 15458.45 & 20314.28 & 25419.80 & 32744.99 \\
Average & 15963.31 & 20879.93 & 26263.75 & 32209.46 \\
& 15549.36 & 20944.09 & 26246.78 & 28935.27 \\
SCC-FC & 14948.76 & 18828.81 & 25878.61 & 31763.77 \\
& 14612.36 & 2010.30 & 25511.97 & 34714.36 \\
& 15036.83 & 19958.06 & 25879.12 & 31804.47 \\
\hline
\end{tabular}




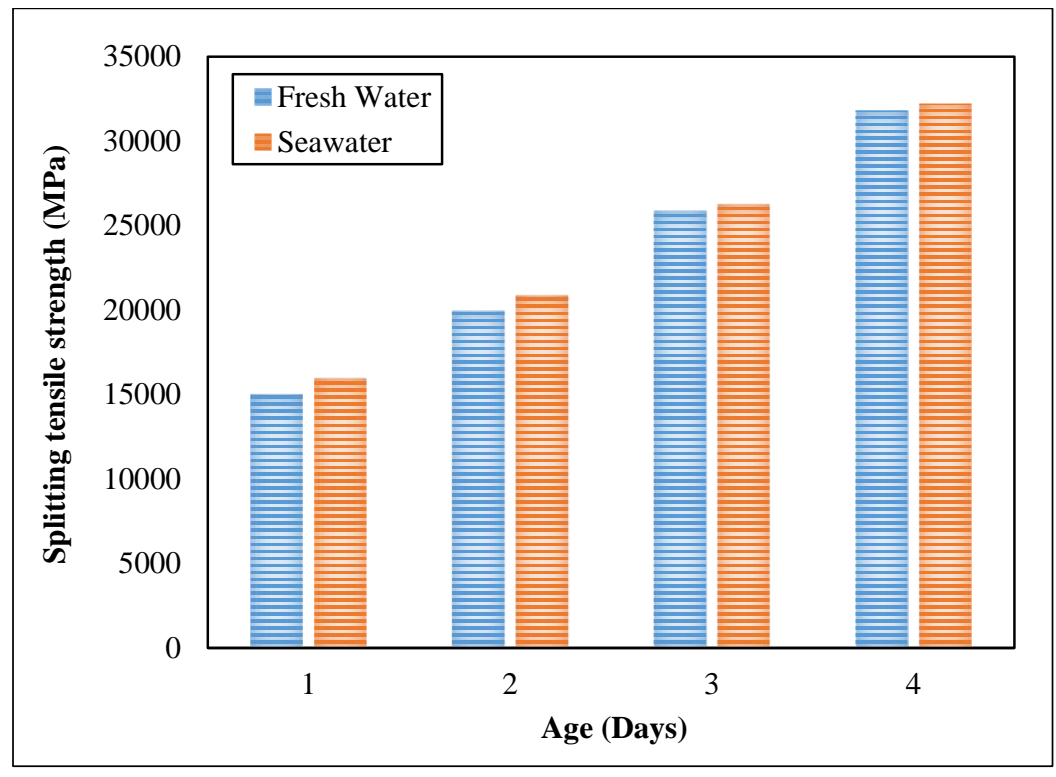

Figure 4. Splitting tensile strength of SCC-FC and SCC-SC

As suggested by Kaushik and Islam [18], higher early-age strength of seawater concrete was attributed to lower porosity due to the acceleration in the hydration. In comparison, the lower long-term strength was attributed to the leaching of the hydration products. Wegian [6] revealed magnesium sulfates $\left(\mathrm{Mg}_{2} \mathrm{SO}_{4}\right)$ in seawater reacts with calcium hydroxide $(\mathrm{Ca}(\mathrm{OH}))$ in the pore solution to form soluble magnesium hydroxide $\left(\mathrm{Mg}(\mathrm{OH})_{2}\right)$ and gypsum $\left(\mathrm{CaSO}_{4} \cdot 2 \mathrm{H}_{2} \mathrm{O}\right)$. These phases may cause expansive crystallization pressure to cause a decrease in concrete strength. While several explanations have been proposed, the decrease likely depends on cement and seawater chemistry, the use of supplementary cementitious materials, and the curing regime used.

\subsection{Microstructure Characteristic}

The microstructure analysis showed some detectable differences between the concretes produced using seawater and freshwater, probably due to the variations in their compositions. Table 3 shows the results for the microstructure analysis on both SCC-SC and SCC-FC at the age of 1 day, 3 days, 7 days, and 28 days. The tobermorite percentage in SCC-SC was found to be higher than in SCC-FC, while the portlandite percentage was shown to be smaller.

The presence of $\mathrm{NaCl}$ was considered the most fundamental component affecting the chemical bonding reaction in the concrete. This research found significant differences in the microstructures of SCC-SC and SCC-FC, including their chloride and Friedel's salt contents. These contents were not detected in concretes made using freshwater but found in those produced with seawater. Meanwhile, compositions of chemical compounds and elements commonly found in concrete were only different in their amounts in both types based on the time applied.

Table 4. Microstructure analysis

\begin{tabular}{|c|c|c|c|c|c|}
\hline \multirow{2}{*}{ Test Sample } & \multirow{2}{*}{ Microstructure phase (\%) } & \multicolumn{4}{|c|}{ Age (Days) } \\
\hline & & 1 & 3 & 7 & 28 \\
\hline SCC-SC & \multirow{2}{*}{ Portlandite, $\left(\mathrm{Ca}(\mathrm{OH})_{2}\right)$} & 10.23 & 9.37 & 7.58 & 6.18 \\
\hline SCC-FC & & 11.09 & 12.28 & 16.80 & 22.0 \\
\hline SCC-SC & \multirow{2}{*}{$\begin{array}{c}\text { Tobermorite } \\
\left(3 \mathrm{CaO} .2 \mathrm{SiO}_{2} .3 \mathrm{H}_{2} \mathrm{O}\right)\end{array}$} & 30.77 & 34.72 & 43.6 & 58.66 \\
\hline SCC-FC & & 29.97 & 31.58 & 39.2 & 51.35 \\
\hline SCC-SC & \multirow{2}{*}{$\begin{array}{c}\text { Friedel's salt } \\
\left(3 \mathrm{CaO} \cdot \mathrm{Al}_{2} \mathrm{O}_{3} \cdot \mathrm{CaCl}_{2} \cdot 10 \mathrm{H}_{2} \mathrm{O}\right)\end{array}$} & 0.3 & 1.39 & 3.25 & 7.71 \\
\hline SCC-FC & & - & - & - & - \\
\hline SCC-SC & \multirow{2}{*}{$\begin{array}{c}\text { Ettringite } \\
\left(3 \mathrm{CaO} . \mathrm{Al}_{2} \mathrm{O}_{3} \cdot \mathrm{CaSO}_{4} .32 \mathrm{H}_{2} \mathrm{O}\right)\end{array}$} & 0.82 & 2.6 & 4.83 & 6.38 \\
\hline SCC-FC & & - & - & - & - \\
\hline SCC-SC & \multirow{2}{*}{ Chloride (Cl) } & 1.75 & 1.26 & 0.17 & 0.05 \\
\hline SCC-FC & & - & - & - & - \\
\hline SCC-SC & \multirow{2}{*}{$\begin{array}{l}\text { Tricalcium silicate } \\
\qquad\left(3 \mathrm{CaO} . \mathrm{SiO}_{2}\right)\end{array}$} & 20.16 & 16.61 & 9.5 & - \\
\hline SCC-FC & & 20.65 & 17.92 & 10.8 & - \\
\hline SCC-SC & \multirow{2}{*}{$\begin{array}{l}\text { Dicalcium silicate } \\
\quad\left(2 \mathrm{CaO} . \mathrm{SiO}_{2}\right)\end{array}$} & 37.72 & 35.31 & 31.2 & 20.93 \\
\hline SCC-FC & & 38.29 & 38.22 & 33.2 & 26.65 \\
\hline
\end{tabular}




\subsubsection{The Effect of Immersion Time on Calcium Hydroxide Formation}

Calcium hydroxide $\left[\mathrm{Ca}\left(\mathrm{OH}_{2}\right)\right]$ is one of the molecules formed from the reaction of elements of silica in cement and water. This molecule is easily reacted with other elements or chemical compounds to give the concrete more strength. Table 4 shows that calcium hydroxide content of SCC-FC increases with increasing immersion time, but it decreases for SCC-SC. This different result was reported by Bachtiar et al. (2014) [12] that calcium hydroxide content of concrete both seawater and freshwater as mixing were increased with increasing immersion time. The molecule of $\mathrm{Ca}(\mathrm{OH})_{2}$ is soluble and easily reacts with other compounds. Through the use of seawater, this molecule reacts chemically with $\mathrm{NaCl}$ to form calcium chloride while with freshwater, the formation value of calcium hydroxide increased due to the reaction between silica elements in cement and water during the given time. On the contrary, this value decrease in concrete made using seawater as the mixing and immersion agents and this might be due to the contamination of chloride or other elements not observed using freshwater.

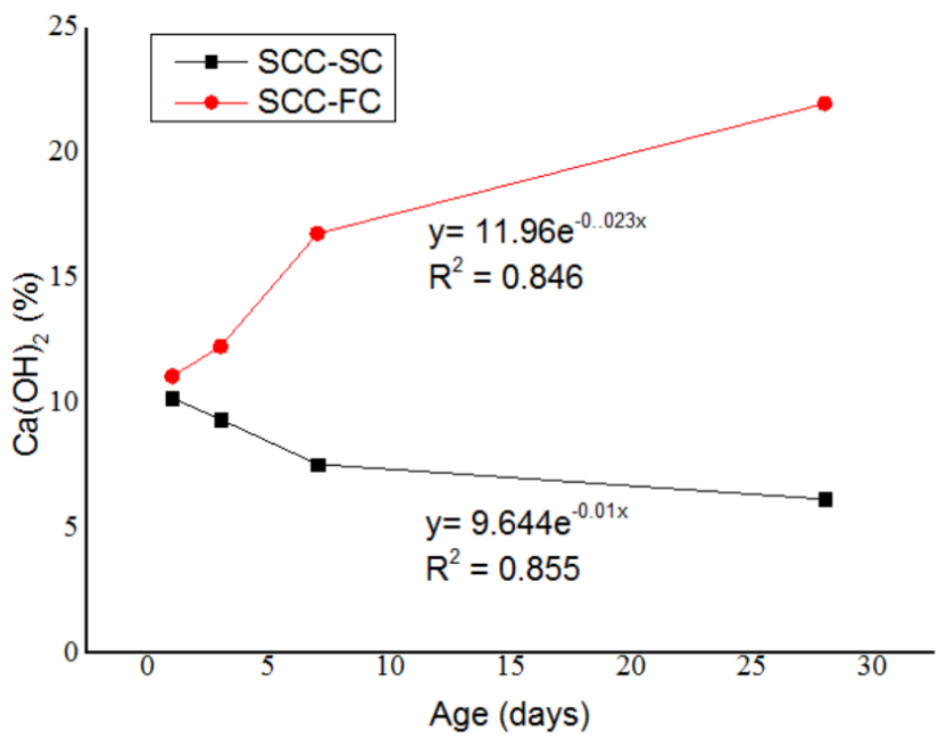

Figure 5. Linear regression model of immersion time and formation of $\mathrm{Ca}(\mathrm{OH})_{2}$

The regression correlation between the immersion time and the formation of calcium hydroxide in SCC-SC is illustrated in Figure 5 to obtain an equation of $y=9.644 \mathrm{e}^{-0.01 \mathrm{x}}$ with a correlation coefficient (r) of 0.925 and determination coefficient $\left(\mathrm{r}^{2}\right)$ of 0.855 . The correlation value obtained indicated a significant effect of immersion time to the formation of calcium hydroxide. This means a more extended period of immersion leads to a longer reaction between calcium hydroxide and chloride element from seawater, thereby, reducing the level of calcium hydroxide in the concrete. Moreover, the determination coefficient obtained showed the effect of immersion time on the formation of calcium hydroxide at a percentage of $85.5 \%$. On the contrary, for the SCC-FC, the correlation value (r) for SCC-FC was found to be 0.920 , indicating a strong correlation between the immersion time and the formation of calcium hydroxide in freshwater concrete. This value implied a more extended period of immersion leads to the formation of more calcium hydroxide. Besides, the determination coefficient of $r^{2}=0,846$ indicated the effect of immersion time to the formation of calcium hydroxide was at $84.6 \%$.

\subsubsection{The Effect of Immersion Time on Friedel's Salt Formation}

$\mathrm{NaCl}$ could react with tricalcium aluminate to form calcium aluminate chloride hydrate (Friedel's salt; the chemical formula is $3 \mathrm{CaO} \cdot \mathrm{Al}_{2} \mathrm{O}_{3} \cdot \mathrm{CaCl}_{2} \cdot 10 \mathrm{H}_{2} \mathrm{O}$ ). Friedel's salt is essential several reasons. First, it is more stable than the hydroxy aluminate. A range of hydroxyaluminates differing in molecular water contents is known, but all are unstable with respect to mixtures of hydrogarnet and alumina hydrate (gibbsite). Second, hydroxyaluminates phases exhibit anion exchange: their composition is sensitive to their local chemical environment. Thus, when chloride diffuses into cement, diffusion profiles may be affected by ion exchange and binding into hydroxyaluminates phases; the hydroxyaluminates serves as a "sink" for chloride ions and thereby retards diffusion of chloride [19].

Friedel's salt only exists in concrete which using seawater as mixing water. The result of the reaction formed between calcium hydroxide and $\mathrm{NaCl}$, called calcium chloride, reacts again with other chemicals present in cement, namely aluminate compounds. As a result of this reaction form Friedel salt, which functions to fill the pores in the concrete. Friedel's salt formation increases with the increasing of immersion time, as seen in Table 4. The correlation between immersion time and formation of Friedel's salt is displayed in Figure 6. It shows the non-linear regression relationship percentage of Friedel's salt and immersion time of SCC-SC. Percentage of Friedel's salt and immersion 
time relationship equation is $\mathrm{y}=0.736 \mathrm{e}^{0.091 \mathrm{x}}$ with a correlation coefficient, $\mathrm{r}=0.821$ and determination coefficient, $\mathrm{r}^{2}=$ 0.647 means that the immersion time has a $67.4 \%$ effect on Friedel salts. Correlation value showed a positive correlation is strong, and this means that the more Friedel salt content in concrete, the more pores in the concrete-filled by it.

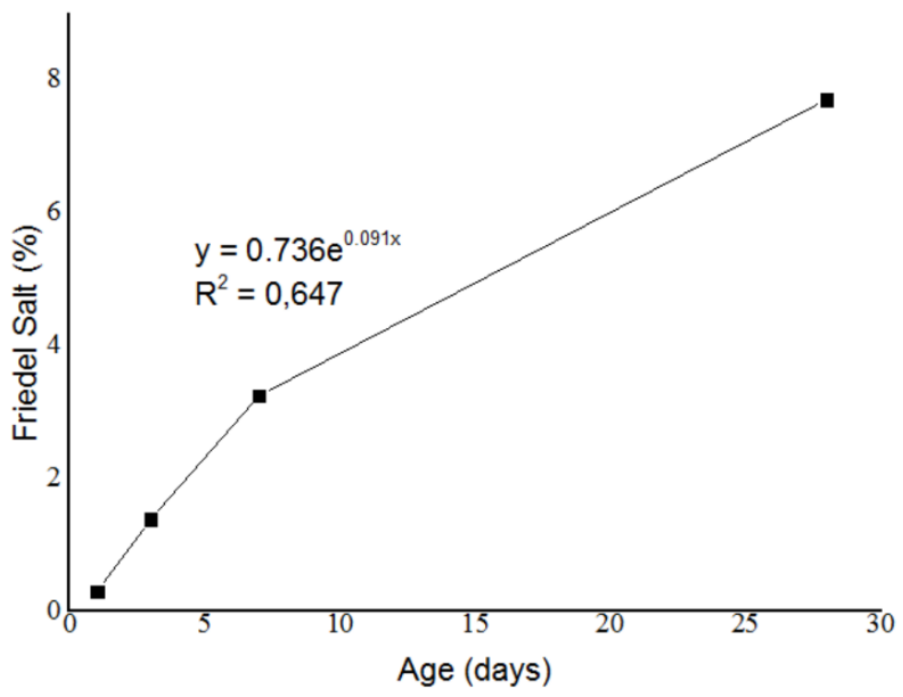

Figure 6. Linear regression model of immersion time and formation of Friedel's salt

\subsubsection{The Effect of Immersion Time on Tobermorite}

The reaction between tricalcium silicate or dicalcium silicate and water led to the formation of tobermorite and calcium hydroxide. As seen in Table 4, that tobermorite content of SCC-SC is a bit higher than SCC-FC. This result similar to reported by Bachtiar et al. (2014) [12] that tobermorite of seawater concrete higher than freshwater concrete. Based on data was obtained, that increasing of tobermorite led to increasing compressive strength and splitting tensile strength of both SCC-SC and SCC-FC. Figure 7 shows the correlation between immersion time and the formation of tobermorite. The results showed more extended immersion of specimen caused the higher formation of tobermorite in the concrete.

Tobermorite or calcium silicate hydrate $(\mathrm{C}-\mathrm{S}-\mathrm{H})$ filled about $70 \%$ of the chemical compounds in concrete and played an important role in compressive strength formation. Furthermore, the regression analysis of the immersion time and formation of tobermorite in the SCC-SC concrete obtained an equation of $\mathrm{y}=32.93 \mathrm{e}^{0.021 \mathrm{x}}$ with a correlation coefficient (r) of 0.945 indicating a strong positive correlation of immersion time and tobermorite formation. Consequently, a longer period of immersion caused more formation of tobermorite. Moreover, the determination coefficient $\left(\mathrm{r}^{2}\right)$ obtained was 0.893 which showed that about $89.3 \%$ of the tobermorite formation was affected by the immersion time. Similar trend was also observed in the SCC-FC concrete with an equation of $y=30.90 \mathrm{e}^{0.018 \mathrm{x}}$, $\mathrm{r}$ at 0.957 , and $r^{2}$ at 0.915 . The value of $r^{2}$ indicated approximately $91.5 \%$ of tobermorite formed was affected by the immersion time.

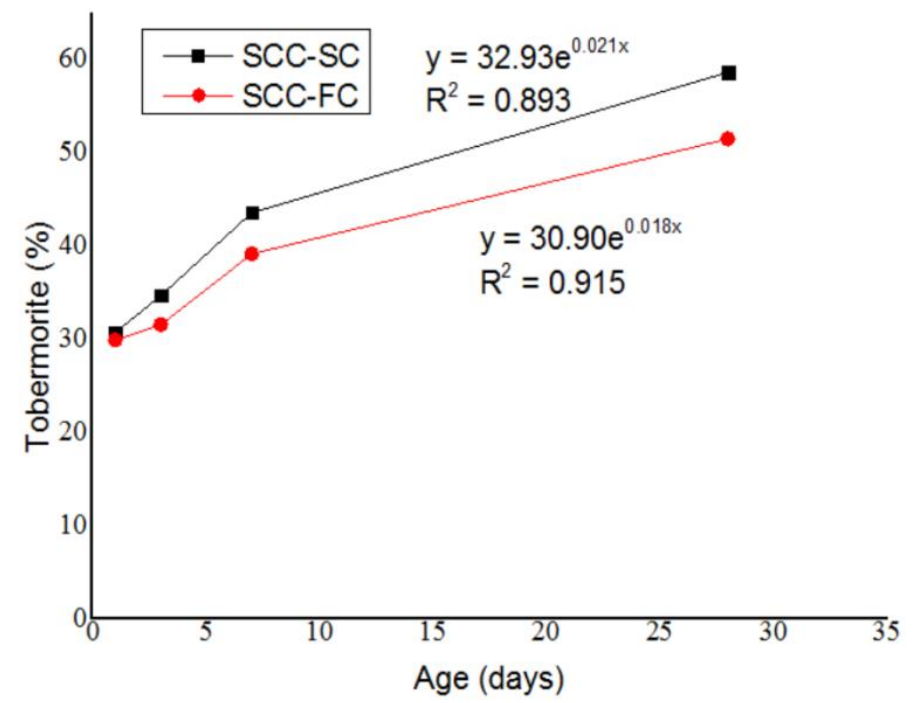

Figure 7. Linear regression model of immersion time and formation of tobermorite 


\section{Conclusions}

- The compressive strength and splitting tensile strength of two types of concretes studied, SCC-SC and SCC-FC, were significantly increased with the immersion time and not significantly different, although the SCC-SC has higher values. The highest compressive strength and splitting tensile strength were $44.8 \mathrm{MPa}$ and 32209.46 Mpa, which obtained for SCC-SC with 28 days immersion time;

- The formation of Friedel's salt was observed in concrete produced from seawater (SCC-SC), thereby binding the chloride to reduce the amount of free chloride and filled the pores of the concrete. The formation of this salt was increased significantly at $7.71 \%$ with decreasing period of immersion for 28 days. On the contrary, Friedel's salt and chloride did not exist in concrete produced from freshwater (SCC-FC);

- The more extended immersion of the specimen leads to the higher forms of tobermorite in concrete. It can be seen that the regression analysis of the immersion time and formation of tobermorite in the SCC-SC concrete obtained an equation of $y=32.93 \mathrm{e}^{0.021 x}$ with a correlation coefficient $(r)$ of 0.945 indicating a strong positive correlation of immersion time and tobermorite formation;

- The interesting thing show for calcium hydroxide $\left(\mathrm{Ca}(\mathrm{OH})_{2}\right)$ formation, the longer immersion of specimen gives different effect to SCC-SC and SCC-FC. The value decrease in concrete made using seawater as the mixing and immersion agents, but an increase in concrete made using freshwater. The formation of calcium hydroxide $\left[\mathrm{Ca}\left(\mathrm{OH}_{2}\right)\right]$ was found to reduce at about $6.18 \%$ due to the chemical bonding with the chloride for SCC-SC;

- In this study, microstructure analysis of the concrete using seawater and freshwater as mixing water did not significantly affect the mechanical behaviour of the concrete. Although, the effect of the chloride and porosity were not examined further in this research.

\section{Conflicts of Interest}

The authors declare no conflict of interest.

\section{References}

[1] Mekonnen, Mesfin M., and Arjen Y. Hoekstra. "Four Billion People Facing Severe Water Scarcity." Science Advances 2, no. 2 (February 2016): e1500323. doi:10.1126/sciadv.1500323.

[2] Nishida, Takahiro, Nobuaki Otsuki, Hiroki Ohara, Zoulkanel Moussa Garba-Say, and Tomohiro Nagata. "Some Considerations for Applicability of Seawater as Mixing Water in Concrete.” Journal of Materials in Civil Engineering 27, no. 7 (July 2015). doi:10.1061/(asce)mt.1943-5533.0001006.

[3] Kucche, K. J., S. S. Jamkar, and P. A. Sadgir. "Quality of water for making concrete: a review of literature." International Journal of Scientific and Research Publications 5, no. 1 (January 2015): 1-10.

[4] Xiao, Jianzhuang, Chengbing Qiang, Antonio Nanni, and Kaijian Zhang. "Use of Sea-Sand and Seawater in Concrete Construction: Current Status and Future Opportunities." Construction and Building Materials 155 (November 2017): 11011111. doi:10.1016/j.conbuildmat.2017.08.130.

[5] Abdulaziz Alrowaih and Ahmad Alruwayeh, "Sea Water Effects on the Mechanical Strength in Concrete on Exposure to Environmental Changes and During Curing," International Journal of Scientific Engineering and Research (IJSER) 6, no. 5 (May 2018): 12-20.

[6] Wegian, Falah M. "Effect of Seawater for Mixing and Curing on Structural Concrete." The IES Journal Part A: Civil \& Structural Engineering 3, no. 4 (November 2010): 235-243. doi:10.1080/19373260.2010.521048.

[7] Teng, Jin-Guang, Yu Xiang, Tao Yu, and Zhi Fang. "Development and Mechanical Behaviour of Ultra-High-Performance Seawater Sea-Sand Concrete." Advances in Structural Engineering 22, no. 14 (July 3, 2019): 3100-3120. doi:10.1177/1369433219858291.

[8] Bachtiar, E., M. W. Tjaronge, R. Djamaluddin, and V. Sampebulu. "Compressive Strength and Slump Flow of Self Compacting Concrete Uses Fresh Water and Sea Water." ARPN Journal of Engineering and Applied Science 10, no. 6 (2015): 2373-2377.

[9] E. Bachtiar, "The Self Compacting Concrete (SCC) using seawater as mixing water without curing," Journal of Engineering Applied Science 13 (July 2018): 4057-4061.

[10] Younis, Adel, Usama Ebead, Prannoy Suraneni, and Antonio Nanni. "Fresh and Hardened Properties of Seawater-Mixed Concrete." Construction and Building Materials 190 (November 2018): 276-286. doi:10.1016/j.conbuildmat.2018.09.126.

[11] Erniati, M.W. Tjaronge, Victor Sampebulu, and Rudy Djamaluddin. "Porosity and Microstructure Phase of Self Compacting Concrete Using Sea Water as Mixing Water and Curing." Advanced Materials Research 1119 (July 2015): 647-651. doi:10.4028/www.scientific.net/amr.1119.647. 
[12] E. Bachtiar, M. W. Tjaronge, R. Djamaluddin, and V. Sampebulu, "Microstructure characteristics of self-compacting concrete using sea water," International Journal of Applied Engineering Research 9, no. 22 (January 2014): 18087-18095.

[13] E. Bachtiar, M. W. Tjaronge, R. Djamaluddin, and V. Sampebulu, Konsistensi dan Kuat Tekan Mortar yang Menggunakan Air Laut Sebagai Mixing Water. In Proceeding of Konferensi Nasional Teknik Sipil 7 (2013), edited by YoyongArfiadi, Geoteknik Material Struktur: 33-37.

[14] Pruckner, F, and O.E Gjørv. "Effect of $\mathrm{CaCl} 2$ and $\mathrm{NaCl}$ Additions on Concrete Corrosivity." Cement and Concrete Research 34, no. 7 (July 2004): 1209-1217. doi:10.1016/j.cemconres.2003.12.015.

[15] M. Aburawi and R. N. Swamy, "Influence of salt weathering on the properties of concrete," Arabain Journal of Science Engineering 33 (April 2008): 105-116.

[16] Park, Sang Soon, Seung-Jun Kwon, and Ha-Won Song. "Analysis Technique for Restrained Shrinkage of Concrete Containing Chlorides." Materials and Structures 44, no. 2 (July 30, 2010): 475-486. doi:10.1617/s11527-010-9642-4.

[17] M. Khatib, F. De Caso y Basalo, and A. Nanni, "SEACON: Redefining Sustainable Concrete," In Proceeding of Sustainable Construction Materials and Technologies, edited by Nader Ghafoori 2016.

[18] Kaushik, S.K., and S. Islam. "Suitability of Sea Water for Mixing Structural Concrete Exposed to a Marine Environment." Cement and Concrete Composites 17, no. 3 (January 1995): 177-185. doi:10.1016/0958-9465(95)00015-5.

[19] Birnin-Yauri, U.A, and F.P Glasser. "Friedel's Salt, $\mathrm{Ca} 2 \mathrm{Al}(\mathrm{OH}) 6(\mathrm{Cl}, \mathrm{OH}) \cdot 2 \mathrm{H} 2 \mathrm{O}$ : Its Solid Solutions and Their Role in Chloride Binding." Cement and Concrete Research 28, no. 12 (December 1998): 1713-1723. doi:10.1016/s00088846(98)00162-8. 